\title{
Journal of Bacteriology and Parasitology
}

\section{Blood-Brain Barrier and Cerebral Malaria: The Road So Far}

\section{Mauro Prato ${ }^{1,2 *}$}

${ }^{1}$ Dipartimento di Neuroscienze, Università di Torino, Torino, Italy

${ }^{2}$ Dipartimento di Scienze della Sanità Pubblica e Pediatriche, Università di Torino, Torino, Italy

Cerebral Malaria (CM) is a life-threatening complication of falciparum malaria, associated with high mortality rates, as well as neurological impairment in surviving patients [1]. According to the World Health Organization (WHO) clinical criteria, CM is defined as a potentially reversible, diffuse encephalopathy causing a Glasgow coma score of 11/15 or less, often associated with fitting, in the absence of other factors that could cause unconsciousness such as coexistent hypoglycemia or other CNS infections [2]. Children from areas endemic for malaria or non-immune adults traveling from developed countries are at higher risk to develop CM. On the contrary, CM is rarely encountered in $>10$-year-old patients who have been exposed to Plasmodium falciparum since birth. Mortality ranges from 15-30\%, and $11 \%$ of children display neurological deficits upon discharge [1].

The pathophysiological mechanisms underlying CM are not fully understood so far. P. falciparum is unique in that it causes mature infected red blood cells to sequester and adhere to cerebral microvascular beds. However, $P$. falciparum appears to remain in the vascular space without ever entering the brain parenchyma, in contrast to other encephalitiscausing pathogens, such as Trypanosoma spp or Toxoplasma gondii [3], thus raising question of how intravascular Plasmodium parasites are capable of inducing such a devastating neural dysfunction in CM. Several authors have implicated blood-brain barrier (BBB) damage as one of the underlying mechanisms of CM, with leaky BBB allowing toxic compounds to enter the brain and cause neurological dysfunction [4-7]. The BBB is constituted of cerebral vascular endothelial cells, which do not form a rigid structure, but rather a dynamic interface with a range of physical, biochemical and immune properties and functions, built from effective inter-cellular junctions and cell-matrix adhesion molecules, enzymes, and trans-endothelial transport systems [8]. In particular, BBB integrity is dictated by tight junctions between adjacent endothelial cells, forming a network of strands composed by several proteins, including junctional adhesion molecules, claudins (mainly -1 and -5 ) and occludin, which interact with cellular actin through cytoplasmic proteins such as zonula occludens-1 [9].

However, there is much discrepancy on the entity of BBB damage between animal and human models of $\mathrm{CM}$ thus far. As recently reviewed [7], a strong $\mathrm{BBB}$ breakdown is recurring in mouse CM models; however, data on increased BBB permeability in human CM are somehow less evident, generally suggesting the occurrence of only mild BBB impairment, characterized by a relevant degree of tight junction disruption, but lacking molecule exchange between serum and cerebral-spinal fluid. The relevance of murine CM models for studying CM pathophysiology has been a topic of big debate in the recent years, since murine CM displays obvious differences and some similarities to the clinical and pathological features of human CM [10,11]. A recurring issue concerns the degree of $i R B C$ sequestration in the brain and other organs of $P$. berghei ANKA-infected mice. Although recent data find increased $\mathrm{iRBC}$ accumulation during murine $\mathrm{CM}$ in multiple organs including the brain, $P$. berghei infection is generally acknowledged to promote marked accumulation of leukocytes, which is in stark contrast with human CM [11]. Additionally, mouse studies suggesting associations between high levels of cytokines and CM have been recently challenged by works showing that high levels of pro- inflammatory cytokines such as TNF- $\alpha$ are poor indicators of human $\mathrm{CM}$ in African children [10]. Thus, future experimental studies on alternative animal models (non-human primates and other mouse models) are encouraged and urgently necessary to better understand the pathological processes underlying human infection [10,11].

Another interesting point emerging from clinical data is that the BBB appears more impaired in children than in adults [7]. Since CM often strikes children at a critical time in brain development, Hawkes and colleagues have nicely hypothesized that developmental changes in the cerebral vasculature may account for some of the differences in disease presentation and outcome between children and adults [12]. The brain develops within an environment that is different from that of the rest of the body, and the developing brain possesses a number of unique features not generally present in the adult [13]. Interestingly, certain genes coding for influx/efflux proteins are expressed at much higher levels early in development than in the adult, and there is physiological evidence that these transport systems are functionally more active in the developing brain [13]. How such differences between the pediatric and adult $\mathrm{BBB}$ can affect $\mathrm{CM}$ pathogenesis and correlate with enhanced $\mathrm{BBB}$ permeability in pediatric $\mathrm{CM}$ is still unknown, and future research aimed at shedding light on this topic will certainly be useful.

Finally, experimental evidence has recently implicated a specific family of host proteolytic enzymes known as matrix metalloproteinases (MMPs) in CM pathogenesis [7,14-17]. MMPs can process a large repertoire of substrates, including pro-inflammatory molecules, tight junctions, and hemostatic factors $[18,19]$ and could play an active role during $\mathrm{CM}$ development by modulating the inflammatory response and the BBB function. Clearly, the idea of using broad spectrum or specific MMP inhibitors as adjuvant therapy in CM appears intriguing. Unfortunately, in the last two decades, a large number of synthetic MMP inhibitors have gone through clinical trials as anti-cancer and anti-arthritis drugs, but largely failed due to serious side effects $[20,21]$. Nevertheless, the side effects of MMP inhibitors were associated with long-term treatment, whereas the time course of drug administration in CM therapy should be reasonably shorter than cancer therapy. Moreover, several artemisinins, currently used for primary therapy of uncomplicated malaria, have displayed MMP-inhibiting properties [22]. Thus, combinations of MMP inhibitors with anti-malarials could justify lower therapeutic doses of both drugs, thereby reducing their potential side effects whilst still enhancing anti-MMP properties by drug synergy. Although the effects of MMP inhibitors in CM have

${ }^{*}$ Corresponding author: Mauro Prato, Department of Neuroscience, University of Turin, Corso Raffaello 30, 10125, Torino, Italy, Tel: 39-011-6708198; Fax: 39-0116708174; E-mail: mauro.prato@unito.it

Received February 24, 2014; Accepted February 26, 2014; Published February 28, 2014

Citation: Prato M (2014) Blood-Brain Barrier and Cerebral Malaria: The Road So Far. J Bacteriol Parasitol 5: e122 doi: 10.4172/2155-9597.1000e122

Copyright: @ 2014 Prato M. This is an open-access article distributed under the terms of the Creative Commons Attribution License, which permits unrestricted use, distribution, and reproduction in any medium, provided the original author and source are credited. 
been scarcely investigated so far, evidence showing improved survival of CM mice after treatment with broad-spectrum MMP inhibitor BB94 appears promising [23]. Future research aimed at determining the exact contribution of each MMP to BBB damage during CM could yield novel insights to develop new adjuvant therapy approaches.

\section{References}

1. World Health Organization (WHO) (2012) World Malaria Report. Geneva: World Health Organization.

2. Zhao J1, Lama M, Korenromp E, Aylward P, Shargie E, et al. (2012) Adoption of rapid diagnostic tests for the diagnosis of malaria, a preliminary analysis of the Global Fund program data, 2005 to 2010. PLoS One 7: e43549.

3. Elsheikha HM1, Khan NA (2010) Protozoa traversal of the blood-brain barrier to invade the central nervous system. FEMS Microbiol Rev 34: 532-553.

4. Coltel N1, Combes V, Hunt NH, Grau GE (2004) Cerebral malaria -- a neurovascular pathology with many riddles still to be solved. Curr Neurovasc Res 1: 91-110.

5. Gitau EN1, Newton CR (2005) Review Article: blood-brain barrier in falciparum malaria. Trop Med Int Health 10: 285-292.

6. Medana IM, Turner GD (2006) Human cerebral malaria and the blood-brain barrier. Int J Parasitol 36: 555-568

7. Polimeni M, Prato M1 (2014) Host matrix metalloproteinases in cerebral malaria: new kids on the block against blood-brain barrier integrity? Fluids Barriers CNS 11: 1

8. Abbott NJ1, Friedman A (2012) Overview and introduction: the blood-brain barrier in health and disease. Epilepsia 53 Suppl 6: 1-6.

9. Luissint AC1, Artus C, Glacial F, Ganeshamoorthy K, Couraud PO (2012) Tight junctions at the blood brain barrier: physiological architecture and diseaseassociated dysregulation. Fluids Barriers CNS 9: 23.

10. Craig AG1, Grau GE, Janse C, Kazura JW, Milner D, et al. (2012) The role of animal models for research on severe malaria. PLoSPathog 8: e1002401.

11. Riley EM, Couper KN, Helmby H, Hafalla JC, de Souza JB, et al. (2010) Neuropathogenesis of human and murine malaria. Trends Parasitol 26: 277-278.
12. Hawkes M1, Elphinstone RE, Conroy AL, Kain KC (2013) Contrasting pediatric and adult cerebral malaria: the role of the endothelial barrier. Virulence 4: 543-555.

13. Ek CJ1, Dziegielewska KM, Habgood MD, Saunders NR (2012) Barriers in the developing brain and Neurotoxicology. Neurotoxicology 33: 586-604.

14. Szklarczyk A1, Stins M, Milward EA, Ryu H, Fitzsimmons C, et al. (2007) Glial activation and matrix metalloproteinase release in cerebral malaria. $\mathrm{J}$ Neurovirol 13: 2-10.

15. Prato M, Giribaldi G (2011) Matrix metalloproteinase- 9 and haemozoin: wedding rings for human host and Plasmodium falciparum parasite in complicated malaria. J Trop Med:628435

16. Geurts N1, Opdenakker G, Van den Steen PE (2012) Matrix metalloproteinases as therapeutic targets in protozoan parasitic infections. PharmacolTher 133 257-279.

17. Piña-Vázquez C, Reyes-López M, Ortíz-Estrada G, de la Garza M, SerranoLuna J (2012) Host-parasite interaction: parasite-derived and -induced proteases that degrade human extracellular matrix. J Parasitol Res:748206

18. Cauwe B1, Van den Steen PE, Opdenakker G (2007) The biochemical, biological, and pathological kaleidoscope of cell surface substrates processed by matrix metalloproteinases. Crit Rev BiochemMolBiol 42: 113-185.

19. Van Lint $P 1$, Libert $C$ (2007) Chemokine and cytokine processing by matrix metalloproteinases and its effect on leukocyte migration and inflammation. $J$ LeukocBiol 82: 1375-1381.

20. Konstantinopoulos PA1, Karamouzis MV, Papatsoris AG, Papavassiliou AG (2008) Matrix metalloproteinase inhibitors as anticancer agents. Int J Biochem Cell Biol 40: 1156-1168.

21. Hu J1, Van den Steen PE, Sang QX, Opdenakker G (2007) Matrix metalloproteinase inhibitors as therapy for inflammatory and vascular diseases. Nat Rev Drug Discov 6: 480-498.

22. Ho WE1, Peh HY2, Chan TK3, Wong WS4 (2013)Artemisinins: Pharmacological actions beyond anti-malarial. Pharmacol Ther

23. Van den Steen PE1, Van Aelst I, Starckx S, Maskos K, Opdenakker G, et al. (2006) Matrix metalloproteinases, tissue inhibitors of MMPs and TACE in experimental cerebral malaria. Lab Invest 86: 873-888. 